\title{
Familial Subsets in Idiopathic Parkinson's Disease
}

\author{
André Barbeau and Madeleine Roy
}

\begin{abstract}
In the present paper we explore in some detail the hypothesis that the presence of familial aggregations in 10-15\% of Parkinson's disease cases is due in great part to the existence of well-defined familial subsets, rather than to chance occurrences. We describe the clinical and genetic characteristics of the two main subsets: "Essential tremor-related Parkinsonism" and the "Familial akineto-rigid Syndrome" previously identified.

The former type of Parkinsonism is associated at random, but with increased frequency, to an autosomal dominant disorder, usually essential tremor but occasionally OPCA. Two possible susceptibility factors were uncovered in this entity: an increased incidence of familial hyperthyroidism (augmentor factor) and a decreased incidence of the generally frequent HLA Haplotypes $A_{1} B_{8}$ or $A_{2} B_{5}$ (Protective factors).

The other presentation, the "familial akineto-rigid syndrome", appears to be a definite disease entity with an autosomal recessive mode of inheritance (normal parents, increased incidence of identical parkinsonism in sibs, increased consanguinity rate in parents). This newly defined disorder deserves much further genetic and biochemical analysis.
\end{abstract}

RÉSUMÉ: Dans le présent article nous avons exploré en détail l'hypothèse selon laquelle l'observation d'incidences familiales chez 10 à 15\% des cas de maladie de Parkinson serait due beaucoup plus à la présence de sousgroupes génétiques définis qu'à la simple coincidence statistique. Nous décrivons les caractéristiques cliniques et génétiques du "Syndrome parkinsonien associé au tremblement essentiel" et du "Syndrome akineto-rigide familial", identifiés précédemment.

La première forme de Parkinsonisme est effectivement associée selon les lois du hasard, mais en fréquence augmentée, à une maladie autosomale dominante qui prend la forme surtout d'un tremblement essentiel, rarement d'une dégénérescence olivo-ponto cérébelleuse. Les deux seuls facteurs de susceptibilité que nous avons identifiés chez ces patients jusqu'à maintenant sont une incidence augmentée d'hyperthyroidie familiale (facteur facilitateur) et une prévalence diminuée de l'un ou l'autre des haplotypes normalement les plus fréquents dans la population: $H L A-A_{1} B_{8}$ ou $A_{2} B_{5}$ (facteurs de protection).

La seconde présentation clinique, le "syndrome akineto-rigide familial", semble être une entité clinico-pathologique réelle avec un mode de transmission autosomal récessif (parents normaux, incidence de Parkinson identique augmentée dans la fratrie, taux de consanguinité élevé). Cette maladie aux cadres nouveaux mérite une analyse clinique, génétique et biochimique beaucoup plus poussée.

Can. J. Neurol. Sci. 1984; 11:144-150

Previous studies from the literature (Kessler, 1978; Barbeau and Pourcher, 1982) have clearly shown that familial aggregations of Parkinson's disease are not rare occurrences. Depending on the series, the percentage of other Parkinson disorders in families where the index case has Parkinson's disease ranges between the extremes of $2.5 \%$ to $94.5 \%$, with a mean of $15 \%$. (Duvoisin et al., 1969; Mjönes, 1949). Our own matched neighbour investigation (see: Barbeau and Pourcher, 1982) revealed that $12.9 \%$ of patients and $5.6 \%$ of controls have one or more first degree relative with an extrapyramidal syndrome resembling Parkinson's disease. Even the recent twin study (Ward et al., 1983) showed that $5.7 \%$ of the parents and $5.7 \%$ of the sibs of affected twins over the age of 60 have Parkinson's disease, whereas only $2.3 \%$ of monozygotic co-twins (1/62) are so affected.

Many explanations have been advanced to account for this observation. The most popular one (Duvoisin et al., 1969) is that this situation is entirely artefactual and due to chance alone. The figures, however, are not all in favour of this explanation as being the only one valid. The prevalence of Parkinson's disease in people over 60 is $1.0 \%$, and the life-time probability of developing Parkinson's disease is $2.5 \%$ (Kurland,
1958). Even at the latter rate, it would require average family sizes larger than 7 to account for a $15 \%$ rate in added Parkinson cases. Another, more probable, explanation is that the high heritability observed is due to a multifactorial etiology, where genetic and environmental factors interplay. Such was the conclusion of two extremely important studies ten years ago (Kondo et al., 1973; Martin et al., 1973). However, both the above explanations are based on the assumption that all so-called "Idiopathic Parkinson's disease" cases are identical. Our working hypothesis, on the contrary, postulates that the 10-15\% familial aggregation rate reflects in fact the presence in the observed population, in addition to the random cases, of subsets of patients with clearly hereditary patterns. Understanding the pathogenesis of these familial subsets may lead to a better comprehension of all cases of Parkinson's disease.

\section{RESEARCh STRATEGY}

If we are right in our hypothesis, the incidence of familial cases should be higher in kindreds where the onset of the disease in the index case is early. Indications to this effect had 
been given by Yokochi and Narabayashi (1981). Our own studies in 135 early-onset families gathered from our clinic and from a mail survey (Barbeau and Pourcher, 1982) confirmed the prediction: in this group, 46 per cent of all patients with early onset Parkinson's disease (before age 40) had a positive family history of extrapyramidal signs. Closer examination of the index cases revealed two clearly different clinical patterns (Fig. 1): most of the index patients had principal symptoms of tremor and rigidity, slow evolution and only late akinesia (Type $A$ evolution); the others started early with akinesia and rigidity and progressed to invalidity despite treatment (Type B evolution). Interestingly, the kind of secondary cases accompanying each type also differed significantly in clinical pattern. Type A index cases were most often seen with tremor patients in their families, while type B patients had other cases of mostly akinetic Parkinsonism within their kinships, and a higher incidence of metabolic disorders. Thus, within the limits of early onset cases of Parkinsonism, we had demonstrated a high familial incidence $(46 \%)$ which clearly surpassed any chance of random occurrence, and two patterns of clinical transmission:

a) One pattern associated tremor predominant Parkinson's disease with a high prevalence of tremor in the family.

b) The other pattern was characterized by the presence of multiple akineto-rigid parkinsonians in the family.

EVOLUTION PATTERNS IN PARKINSON'S DISEASE

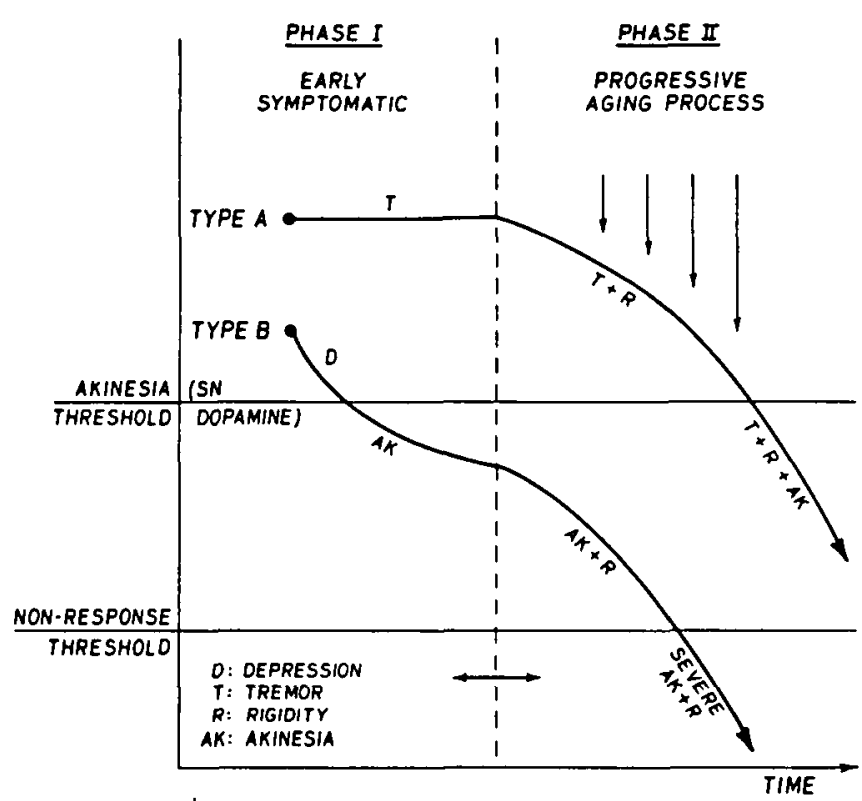

Figure I - Two types of evolution patterns seen in Parkinson's disease. Well-being in Type A pattern is of much longer duration.

These observations on two possible familial subsets were then confirmed in a prospective study of 50 "familial Parkinsonism" kindreds, compared to 50 kindreds with essential tremor and 50 control kindreds (Roy et al., 1983). The relative increased incidence of additional Parkinson cases in 50 index kindreds was quite apparent (Table 1), the relative ratio being 9.5 in first degree relatives and 3.7 in distant relatives. The surprise of this study was the high frequency of essential tremor in relatives of true Parkinson's disease cases, particularly those with a predominance of tremor. The breakdown of the 50 familial Parkinson's disease cases is instructive and illustrated in Fig. 2.
Table 1: Incidence of additional cases

\begin{tabular}{lccccc}
\hline \hline & \multicolumn{4}{c}{ Additional Cases in Kindred } \\
\cline { 2 - 3 } \cline { 5 - 6 } & \multicolumn{2}{c}{ Immediate family } & \multicolumn{2}{c}{ Distant family } \\
\hline & 19 & 48 & 11 & 52 \\
\hline $\begin{array}{c}\text { A. } 50 \text { kindreds with } \\
\quad \text { Parkinson }\end{array}$ & E.T. & Parkinson & E.T. \\
$\begin{array}{l}\text { B. } 50 \text { kindreds with } \\
\text { essential tremor }\end{array}$ & 3 & 112 & 5 & 66 \\
C. 50 control kindreds & 2 & 3 & 3 & 3 \\
\hline
\end{tabular}

It is seen that in 36 instances, the index case was accompanied by essential tremor cases, and occasionally by some examples of true Parkinson's disease. In 14 instances the familial aggregation consisted only of cases of Parkinson's disease. Thus this larger study again confirmed the existence, within the group of "familial parkinsonism ", of two principal subsets:

(1) "Essential tremor-related" Parkinsonism (10\% of cases)

(2) "Familial akineto-rigid Syndrome" (4\% of cases)

More recent studies, now to be reported, will attempt to further define the clinical and genetic characteristics of these principal subsets and of some variants also uncovered.

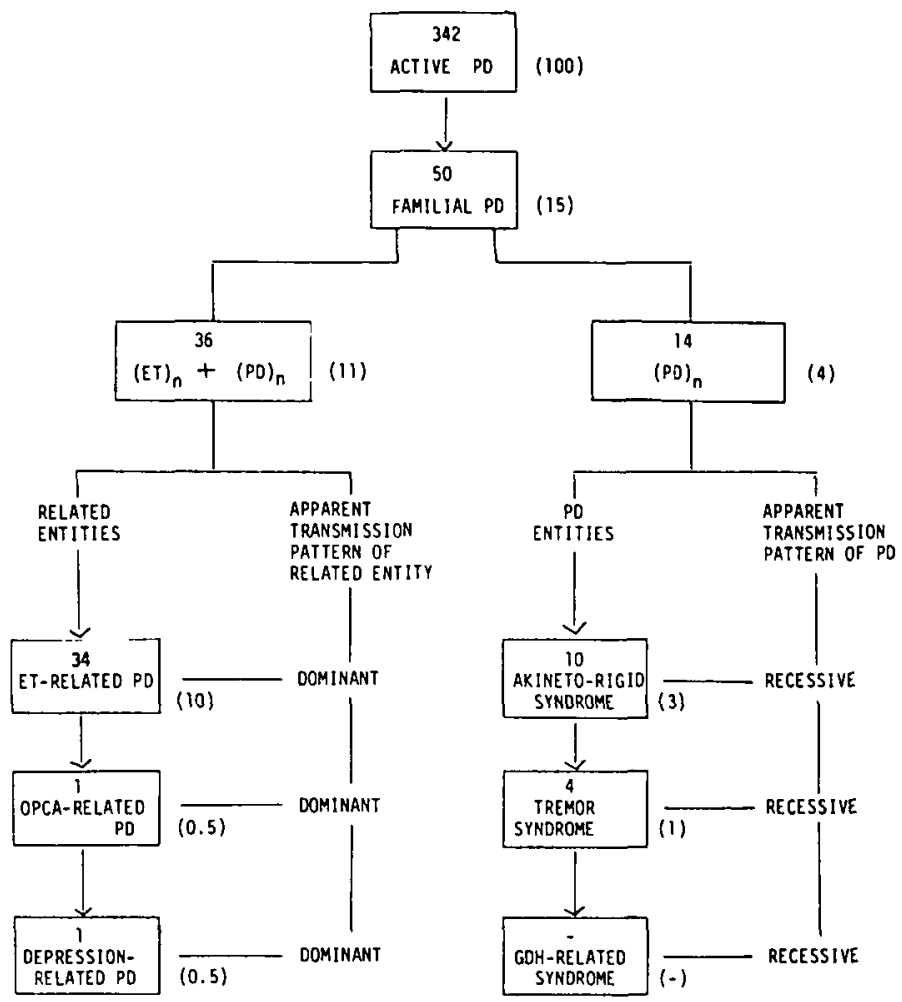

Figure 2-Breakdown of the clinical subsets observed in a survey of 342 kindreds with Parkinsonism. The apparem transmission pattern of the entities thus described is also given.

\section{A. Clinical characterization of subsets}

\section{(1) Subset 1: Essential tremor-related Parkinsonism}

This is the most frequent occurrence in the families we surveyed. In fact it affects nearly $10 \%$ of all cases of idiopathic 
Parkinson's disease. The index case is almost always a moderately aged man or woman (average age of onset $51.5 \mathrm{yrs}$ ) who first notices a tremor in one limb, with a progressive change in the ability to write and a decrease in the swing of the arm. Often this initial symptom is accompanied, or even preceded, by a painful shoulder bursitis. Retrospective questioning reveals the fact that relatives and friends, and less frequently the patient himself, had noted in the patient occasional fine tremor of the hands, or head, in past stressful situations or after surgery. Further probing soon uncovers the existence of one or more close relatives with various tremor syndromes, and occasionally with true Parkinson's disease. Most of the time the hereditary pattern of the tremor in these families is autosomal dominant (Fig. 3), and the clinical presentation fairly uniform except for the apparently random occurrence of full blown Parkinson's disease with an incidence greater than that expected by chance.

\section{FAMILIAL PARKINSON'S DISEASE}

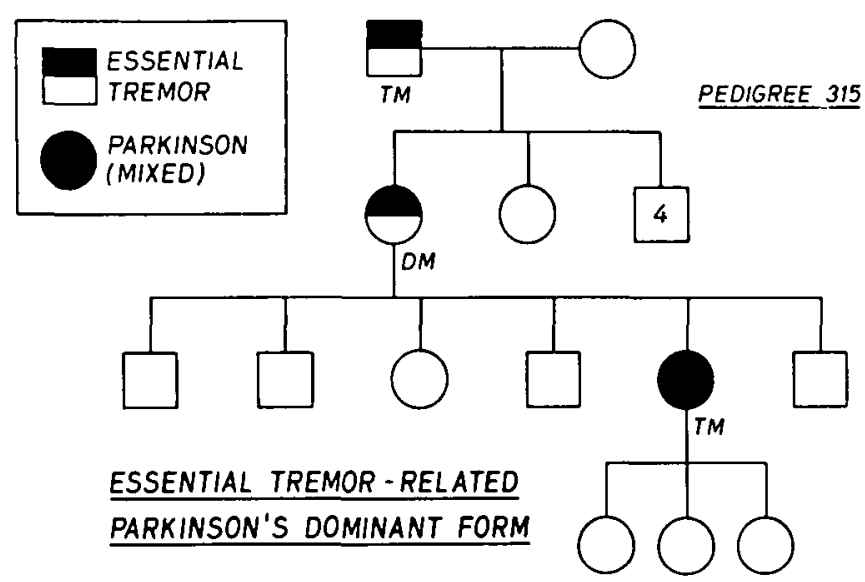

Figure 3 - Typical inheritance pattern of 'Essential-tremor related' Parkinsonism.

In these patients akinesia is rare, or appears only late in the disease as a complication of age-related processes. The progression of the disorder is slow and the patients may survive to fairly advanced ages (Type A evolution). Upon examination, the predominant symptom is tremor in one or all limbs, accompanied by various degrees of limb rigidity, the latter best evidenced by the Noika-Froment maneuver, by a fixed stare, by the classical "démarche à petits pas" and by micrography. The tremor is often of two types: a slow resting tremor fully characteristic of Parkinson's disease and, with the arms extended, a fine, rapid action and postural tremor of the hands. Rarely the head or chin are also involved in this fine rapid tremor.

Lastly, we were able to demonstrate in these families, and in the patients, an increased incidence of hypertension, of hyperthyroidism and of vitiligo, the significance of which still eludes us (Barbeau et Pourcher, 1982).

\section{(2) Subset IA - Depression-related Parkinsonism}

A rare variant of this association was first described by Perry et al. (1975), and a further family by Tune et al. (1982). We also reported one instance of this syndrome (Roy et al., 1983) (Fig. 4). In these families the symptoms of recurrent depression regularly precede those of Parkinsonism. Both are usually combined after the age of $\mathbf{6 0}$ and the pattern of transmission appears to be autosomal dominant. At least in our family, in that of Perry et al. (1975) and in that of Purdy et al. (1979), early symptoms included a fine rapid essential tremor. Late, but rarer symptoms, could be alveolar hypoventilation and sudden death.

\section{FAMILIAL PARKINSON'S DISEASE}

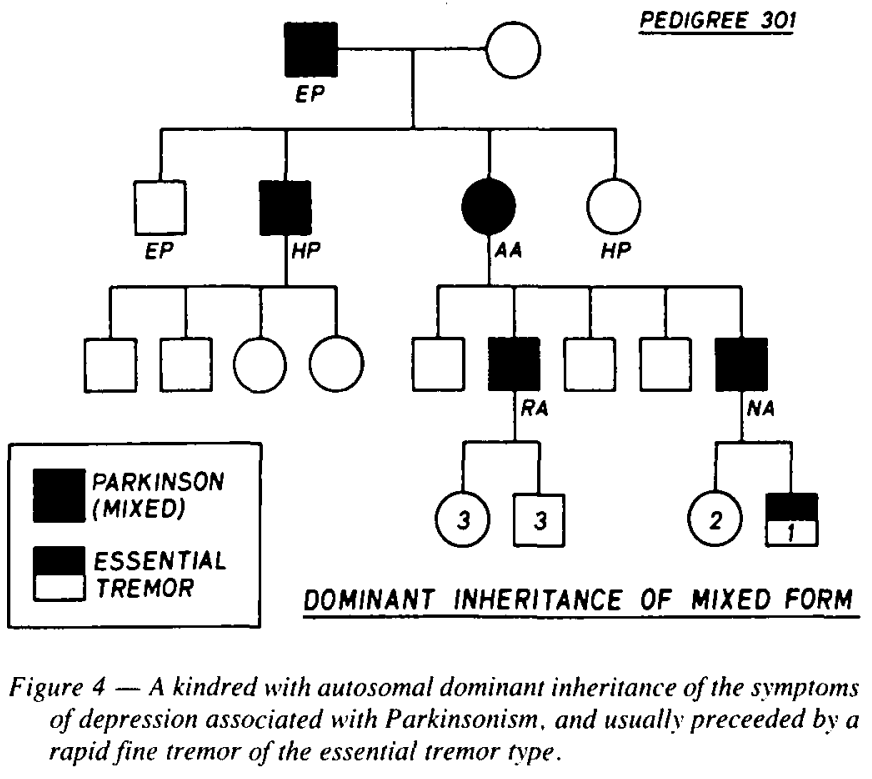

\section{(3) Subset 1B - OPCA-related Parkinsonism}

In the course of our survey, we encountered one family where Parkinsonism occurred in association with familial, autosomal dominant, olivo-ponto-cerebellar atrophy instead of essential-tremor (Fig. 5). This association is well-known, of course, as an evolutionary event in a single patient but this is probably the first instance of a subject with features of both OPCA, inherited from the mother, and of Parkinsonism, inherited from the father. The OPCA family is well-known to us and has previously been reported (Wastiaux et al., 1978). The particular instance of the combination will be reported elsewhere.

\section{(4) Subset 2- "Familial akineto-rigid Syndrome"}

$4 \%$ of the 342 families surveyed presented with aggregation of Parkinsonism without essential tremor. In $3 \%$ of cases the picture was that of severe, relatively rapidly progressive, akinesia. The index patients (average age of onset $52.5 \mathrm{yrs}$ ) have a significant previous history which does not include the presence of essential or volitional tremor. On the other hand these patients had frequently complained of previous episodes of depression, and headaches. Autonomic symptoms are also found in increased frequency: diaphoresis, parasthesiae, pain, impotence and burning sensations are present many years before a diagnosis is made in the majority of cases. Finally, mild bilateral akinesia is usually the first symptom.

Once the disease process has become obvious, akinesia remains, by far, the predominant symptom, accompanied as time progresses by a gradually more severe rigidity (Type B evolution). Tremor, if present, is only a late, and mild symptom. It is interesting to note that dysarthria, stuttering and pallilalia are frequent early symptoms and that they usually increase 
with time. These patients have early insomnia and mild to moderate evidence of dementia. such as paranoia, confusion, hallucinations and intolerance to anticholinergic medication. On the other hand their response to Levodopa is at first excellent but, usually within two years, there is appearance of severe dyskinesia, on-off phenomena and lack of reactivity. One often witnesses a catastrophic progression to invalidity. In these features, our patients resemble the cases of familial juvenile Parkinsonism (Yokochi and Narabayashi, 1981).

The clinical picture in secondary cases within these families is strikingly similar. Whenever tremor is present, it is always as part of a mixed picture with rigidity and akinesia equally prominent. It is of interest that our survey (Roy et al., 1983) has revealed an increased incidence of metabolic disorders (hypothyroidism, diabetes) within these families and in some of the patients.

\section{OPCA-RELATED PARKINSONISM SUMMARY CHART}

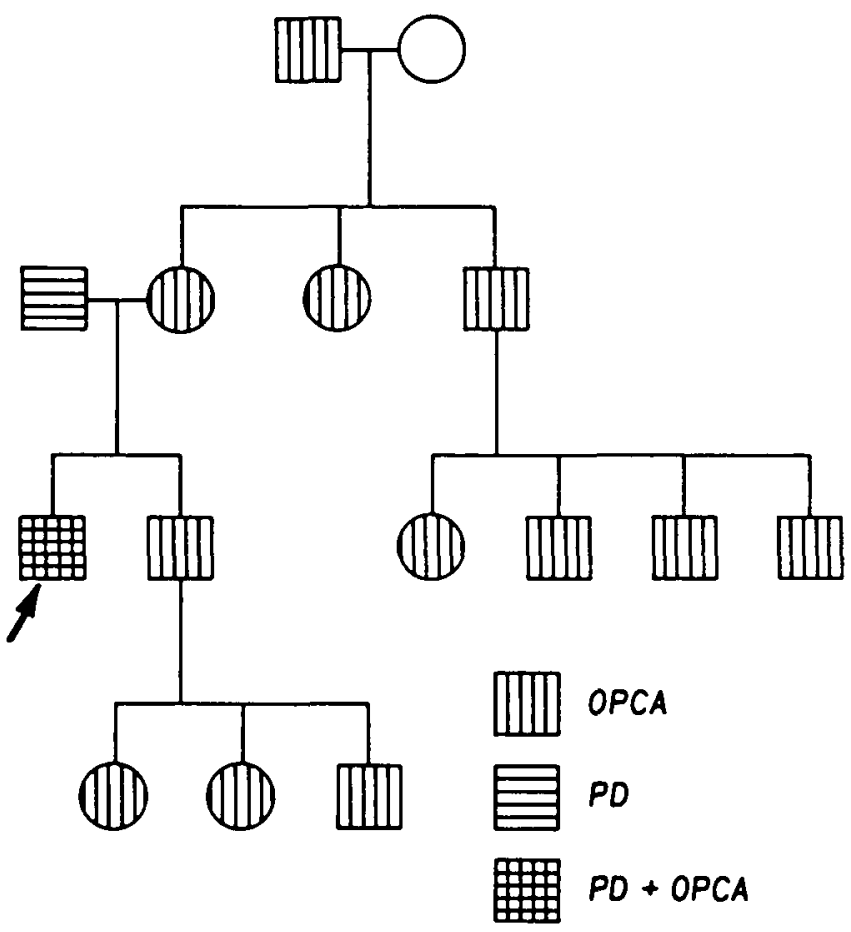

Figure $5-A$ kindred where the index patient apparently inherited the OPCA trait from his mother and the Parkinson trait from his father. The index patient combined symptoms of both disorders.

\section{(5) Subset 2A: “Familial tremor' Syndrome}

Rare instances of classical tremor-predominant Parkinson's disease (or mixed-form Parkinsonism with rigidity and tremor), are seen exclusively in sibs. It is not yet clear whether this presentation is a real syndrome, or just a variant of the essentialtremor related Parkinsonism previously described, but with no evidence of essential tremor in the immediate family.

(6) Subset $2 B-$ “GDH - deficient recessive O.P.C.A.",

Although we did not have the opportunity to observe this occurrence in our own survey, we should include at this point the entity described by Plaitakis et al. (1983). These patients are not the same as those described by us in subset 1B. The olivoponto-cerebellar atrophy is of type Il (Konigsmark and Weiner, 1970), that is, autosomal recessive in inheritance. The patients present symptoms of Parkinsonism associated with the ataxia and dysarthria of OPCA.

\section{B. Genetic characterization of subsets}

\section{(1) Subset 1: Essential-tremor related Parkinsonism}

As stated previously, Parkinsonism appears at random but with increased frequency within families where the essential tremor trait or similar traits like OPCA are transmitted as an autosomal dominant. The problem therefore resides in finding the factor or factors responsible for the increased susceptibility to Parkinsonism in such entities.

a) One possible factor was uncovered in our survey: the increased incidence of hyperthyroidism. Thus in 17 such families studied (Barbeau and Pourcher, 1982), 27 per cent of the index patients had a history of hyperthyroid goitre. As is usually the case, a similar pathology was equally present in $27 \%$ of their mothers and in maternal relatives for a similar percentage $(27 \%)$ of the index cases. The role of a maternally transmitted augmentor factor should therefore be considered in further investigations. (Fig. 6).

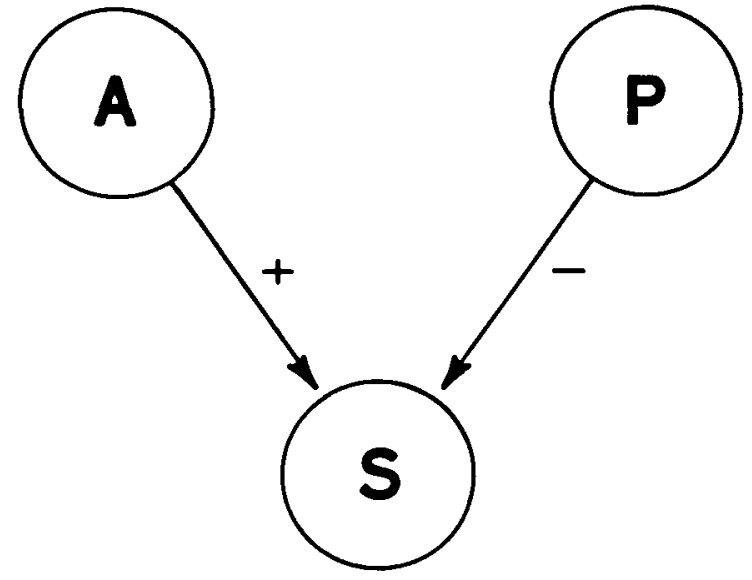

S: SUSCEPTIBILITY FACTOR

\section{A: AUGMENTOR FACTOR \\ $P$ : PROTECTIVE FACTOR}

Figure 6 - Interplay of factors determining the background for the susceptibility to Parkinson's disease. The disease itself would appear only after the added action of cumulative injuries due to environmental factors.

b) When one studies possible susceptibility factors for a disease entity, one must look at the Histocompatibility Complex (HLA). Many studies of HLA in Parkinsonism have been published, with variable results. Some authors have suggested possible increased associations of Parkinson's disease with HLA antigens: $A_{2}, A_{28}$, (Dawidovitz et al., 1977); $B_{17}, B_{18}$ (Emile et al., 1977), $B_{7}$ (Martilla et al., 1981); $B_{14}$ (Elizan et al., 1980) $A_{w} 24$ (Reed et al., 1983) and $A_{3}, A_{28}, B_{w} 21$ (Leheny et al., 1983). Other authors have found decreased incidence of association with: $B_{w} 35$ (Emile et al., 1977; Martilla et al., 1981) $A_{11}, C_{w} 4$ (Martilla et al., 1981). Finally other authors, particularly when 
they applied the proper correction for number of antigens tested (Svejgaard et al., 1974), could not demonstrate any significant association between Parkinson's disease and HLA antigens (Elizen et al., 1980; Lees et al., 1982; Takagi et al., 1982).

Table 2: HLA in Idiopathic Parkinson (pooled results from 123 cases (1)(2)(3)

\begin{tabular}{|c|c|c|c|c|}
\hline \multirow[b]{2}{*}{ Group } & \multicolumn{2}{|c|}{ Controls (\%) } & \multicolumn{2}{|c|}{ Parkinson (\%) } \\
\hline & 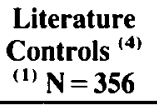 & $\begin{array}{c}\text { Personal } \\
\text { Controls } \\
\mathbf{N}=\mathbf{4 8 8} \\
\end{array}$ & $\begin{array}{c}\text { Personal } \\
\text { Series }{ }^{(1)} \\
\mathrm{N}=\mathbf{4 2} \\
\end{array}$ & $\begin{array}{c}\text { Pooled } \\
\text { Series } \\
N=123 \\
\end{array}$ \\
\hline$A_{1}$ & 28.9 & 25.0 & 14.3 & 25.2 \\
\hline$A_{2}$ & 52.2 & 43.0 & 52.4 & 44.7 \\
\hline$A_{3}$ & 24.7 & 22.3 & 16.7 & 29.3 \\
\hline$A_{9}$ & 13.7 & 10.4 & $4.9^{*}$ & $2.4^{*} \dagger$ \\
\hline$A \omega_{24}$ & 4.7 & 10.9 & 16.7 & $12.2^{*}$ \\
\hline$A_{28}$ & 3.6 & 5.7 & 9.5 & $10.6^{*}$ \\
\hline$A \omega_{32}$ & 1.6 & 7.0 & 9.5 & $7.3^{*}$ \\
\hline $\mathrm{B}_{5}$ & 14.3 & 16.8 & 16.7 & 8.1 \\
\hline$B_{7}$ & 25.5 & 21.7 & 11.8 & 15.4 \\
\hline $\mathbf{B}_{\mathbf{8}}$ & 22.4 & 18.2 & $4.8^{*}$ & 15.4 \\
\hline$B_{12}$ & 31.7 & 24.8 & 38.1 & 36.6 \\
\hline$B_{14}$ & 7.8 & 8.0 & 9.5 & 7.3 \\
\hline$B_{15}$ & 13.4 & 7.8 & 7.1 & 4.9 \\
\hline$B \omega_{17}$ & 7.0 & 7.6 & 7.1 & 11.4 \\
\hline$B_{18}$ & 10.9 & 9.8 & 7.1 & 8.1 \\
\hline $\mathrm{B} \omega_{21}$ & 5.3 & 4.3 & 2.4 & 1.6 \\
\hline $\mathrm{B} \omega_{35}$ & 12.9 & 15.6 & 19.0 & 15.4 \\
\hline
\end{tabular}

(1) Personal series, $\mathrm{N}=42 ; 29$ antigens tested

(2) Elizan et al., 1980, $\mathrm{N}=17 ; 33$ antigens tested

(3) Leheny et al., 1983, $\mathrm{N}=64 ; 23$ antigens tested

(4) Madigand et al., 1982, $\mathrm{N}=356 ; 34$ antigens tested

(5) * Significant uncorrected $\rho$ value

(6) $†$ Significant corrected $\rho$ value

Our own results are worth discussing here (Table 2 ). With the collaboration of Drs. J.P. Wastiaux and G. Lamoureux (Institut Armand Frappier), we were able to test 42 idiopathic Parkinson disease patients ( 34 of which were from subset l-type families) for 29 HLA antigens. We were also able to pool our data with those of previous authors (Elizan et al., 1980; Lehany et al., 1983) who were kind enough to send us the individual results of their series. In Table 2, it can be seen that, of all the types previously reported as sometimes modified, only two: $A_{9}$ and $\mathrm{B}_{8}$, were decreased in our patients $\left(X^{2}\right.$ greater than $\left.4.0 ; \mathrm{p}<0.05\right)$. Again, in our personal series, none were increased. In the pooled series, $A_{9}$ is decreased significantly and $A_{w} 24, A_{28}$, $A_{w} 32$ are increased. After correction for the number of antigens tested, only the decrease in $A_{9}$ remains significant $\left(X^{2} 12.43\right.$,

Table 3: Principal HLA haplotypes in Idiopathic Parkinson's disease.

\begin{tabular}{lccccc}
\hline \hline Haplotype & Trend & $\begin{array}{c}\text { Terasaki } \\
\text { Controls } \\
(\%)\end{array}$ & $\begin{array}{c}\text { Personal } \\
\text { Series } \\
(\%) \\
\mathbf{N = 4 2}\end{array}$ & $\begin{array}{c}\text { Other } \\
\text { Series } \\
(\%) \\
\mathbf{N = 8 1}\end{array}$ & $\begin{array}{c}\text { Total } \\
\text { Pooled } \\
(\%) \\
\mathbf{N}-123\end{array}$ \\
\hline $\mathrm{A}_{1} \mathrm{~B}_{7}$ & - & 0.9 & 2.4 & $6.2^{* \dagger}$ & $4.8^{*}$ \\
$\mathrm{~A}_{1} \mathrm{~B}_{8}$ & - & 12.0 & $2.4^{*} \dagger$ & 11.1 & $\mathbf{8 . 1}$ \\
$\mathrm{A}_{1} \mathrm{~B}_{5}$ & - & 11.2 & 9.5 & $2.5^{*}$ & $4.8^{*} \dagger$ \\
$\mathrm{A}_{2} \mathrm{~B}_{7}$ & & 6.7 & 9.5 & 8.6 & 8.9 \\
$\mathrm{~A}_{2} \mathrm{~B}_{15}$ & & 5.7 & 4.8 & 3.7 & 4.1 \\
$\mathrm{~A}_{2} \mathrm{~B}_{40}$ & & 5.3 & 9.5 & 6.2 & 7.3 \\
$\mathrm{~A}_{3} \mathrm{~B}_{7}$ & & 6.7 & 4.8 & 6.1 & 5.7 \\
\hline
\end{tabular}

${ }^{*}$ Chisquare significant (uncorrected $\rho$ )

†Significant (corrected $\rho$ ) $p<0.01$ ). This antigen had not been looked at in other series. The other 12 antigens tested by us and not reported in Table 2 are all normal.

More significant results appear when Haplotype disequilibria are considered. As can be seen in Table 3, the HLA Haplotype $A_{1} B_{7}$ is significantly increased in the other series in the pool, but not in ours. On the other hand $A_{1} B_{8}$ is significantly decreased in our patients, while $A_{2} B_{5}$ is significantly decreased in the other series and also in the pooled results. The physiologic meaning of a decrease in haplotypes is not entirely clear, but one can postulate that the most common haplotype disequilibria in Caucasians $\left(A_{1} B_{8} ; A_{2} B_{5}\right.$, respectively present in $12.0 \%$ and $11.2 \%$ of the population) should confer some degree of biological advantage (Eeg-Olofsson et al., 1982). A decrease in the incidence of these haplotypes could correspond to the loss of a "protective factor" (Fig. 6) and thus permit the development of the premature aging process which we have previously proposed for the pathogenesis of Parkinson's disease (Barbeau, 1973).

In conclusion, within the subset of the so-called "Essentialtremor related"' syndrome, the Parkinsonian cases appear at random, but with increased frequency. Whether or not this increased propensity is related to certain deficiencies in HLA haplotypes still has to be investigated in larger series, but is a distinct possibility which we would like to propose for study.

Table 4: Relative occurrence of Parkinson in sibs of 50 Parkinsonian index cases

\begin{tabular}{lcr}
\hline \hline - Total number of sibs: & 312 & \\
- Added PD cases: & $18(5.8 \%)$ & \\
- A) Sibs over age 60: $\quad 127$ & $3(2.5 \%) ;$ \\
Predicted number of added PD: & $14(11.0 \%)$; \\
Observed number of added PD: & \\
B) Sibs under age 60: 147 & $1.5(1.0 \%)$; \\
Predicted number of added PD: & \\
Observed number of added PD: & \\
- Clinical presentation of added PD in sibs: & \\
a) Tremor - rigidity: & 4 & \\
b) Akineto-rigid: & 14 &
\end{tabular}

\section{(2) Subset 2: Familial akineto-rigid Syndrome}

An analysis of 50 sibships of Parkinsonian index cases (Table 4) indicated that $11.0 \%$ of the sibs over age $60(14 / 127)$ and $2.7 \%$ of the sibs under age $60(4 / 147)$ also had true Parkinson's disease. Of the 18 additional, or secondary, cases thus discovered, 14 presented in fact with a clinical picture strikingly similar to that of the index cases, ie: predominant akinesia and rigidity. In all instances both parents were entirely free of symptoms, neither Parkinsonism nor essential tremor having been found, or recorded. Furthermore it is clear that the observed incidence exceeds the maximum numbers expected from Kurland's (1958) predictions $(1.0 \%$ for the population at 60 and $2.5 \%$ over a life-time).

Observation of the inheritance pattern in the 14 sibships with the akinetic syndrome indicated that an autosomal recessive heredity was the most likely. Indeed, in these 14 sibships we found 16 secondary cases among the 73 sibs having reached the age of $40(21.9 \%)$. If we include the index cases, the observed rate is now $30 / 87(34.5 \%)$. The postulated mode of inheritance 
was confirmed by a study of the consanguinity rate (Table 5). It is seen that the prevalence of first and second cousin marriages in the parents of this subset reached $28.6 \%(4 / 14)$; whereas this figure was $2.8 \%$ in the essential tremor-related syndrome, this last figure not significantly different from the $2 \%$ found in control subjects and in essential tremor without Parkinson's disease. As a further control, it is also seen that Laberge (1966) had reported an overall consanguinity rate of $2.97 \%(1.04 \%$ urban; $4.24 \%$ rural) in the same French Canadian population.

\begin{tabular}{|c|c|c|c|c|}
\hline Group & $\underset{\text { Marriages }}{\mathbf{N}}$ & $\begin{array}{c}\text { 1st-2nd } \\
\text { Cousins } \\
\text { (n) }\end{array}$ & $\begin{array}{c}\text { Known } \\
\text { Distant } \\
\text { Cousins (n) }\end{array}$ & $\begin{array}{l}\% \text { 1st-2nd } \\
\text { Cousins }\end{array}$ \\
\hline 1. Control & 50 & 1 & 2 & 2.0 \\
\hline 2. Essential tremor & 50 & 1 & 5 & 2.0 \\
\hline $\begin{array}{l}\text { 3. Parkinson } \\
\text { - ET-related }\end{array}$ & 50 & 5 & 1 & 10.0 \\
\hline $\begin{array}{l}\text { syndrome } \\
\text { - Akinetic } \\
\text { syndrome }\end{array}$ & $\begin{array}{l}36 \\
14\end{array}$ & $\begin{array}{l}1 \\
4\end{array}$ & 1 & $\begin{array}{c}2.8 \\
28.6^{*}\end{array}$ \\
\hline $\begin{array}{l}\text { 4. French Canadian } \\
\text { - Urban } \\
\text { - Rural } \\
\text { - Total }\end{array}$ & $\begin{array}{c}\text { Controls (L } \\
32,997 \\
49,710 \\
82,707\end{array}$ & berge, 19 & & $\begin{array}{l}1.04 \\
4.24 \\
2.97\end{array}$ \\
\hline
\end{tabular}

A further argument in favour of an autosomal recessive mode of inheritance is derived from a preliminary study of similar sib-pairs carried out by Reed et al. (1983). In that investigation there were 8 affected sib-pairs in 64 index families $(12 \%)$. None $(0 \%)$ of the pairs shared 0 haplotypes; $3(37.5 \%)$ shared 1 haplotype and $5(62.5 \%)$ shared 2 haplotypes. The predicted distribution should have been $2,4,2$ for the same categories $\left(X^{2}=3.43\right)$. A similar study is now underway in our 14 akineto-rigid sibships.

In summary, the familial akineto-rigid syndrome appears to be a definite clinical entity, although rare (circa $3 \%$ of all parkinsonians). This subset seems to be inherited according to an autosomal recessive pattern. We will be concentrating our further efforts on the genetic and biochemical characterization of this new disease entity.

\section{Conclusions}

Our basic hypothesis was that the observed $10-15 \%$ rate of familial aggregation in most series of Parkinsonian patients was more than just a random, or chance, occurrence. In the present paper we describe a certain number of clinical subsets, the existence of which would indeed account for such observations. In the most frequent entity ( $10 \%$ of all Parkinsonian subjects), "essential-tremor related Parkinsonism", we are able to see the forces at work which permit the increased incidence of true Parkinson's disease within families with well-defined autosomal dominant disorders affecting the same area of the brain stem, such as essential tremor or OPCA. Augmentor factors (such as familial hyperthyroidism) as well as the lack of protective factors (decreased prevalence of generally frequent HLA haplotypes which may confer a biological advantage) may interplay with still unknown environmental factors to explain the increased susceptibility to Parkinson's disease (Fig. 6).
The second major conclusion of our study is the demonstration of the existence of a clearly-defined clinical entity with an apparent autosomal recessive mode of transmission: the familial akineto-rigid syndrome. This syndrome involves $3-4 \%$ of all Parkinsonian patients, and possibly more if akineto-rigid (Type $B$ evolution) singlets are examples of the same biochemical defects, which still must be identified.

With this view we can now justify the more detailed classification of Parkinsonism given in Table 6.

Table 6: Classification of "Parkinsonism"

TYPE I: POST ENCEPHALITIC

TYPE II: IDIOPATHIC
a) Tremor-predominance
b) Akineto-rigid predominance

TYPE III: FAMILIAL
a) PD associated with autosomal dominant diseases
1) Essential-tremor related Parkinsonism
2) OPCA-related Parkinsonism
3) Depression-related Parkinsonism
4) Familial Parkinsonism with peripheral neuropathy

b) PD with autosomal recessive pattern

1) Familial akineto-rigid syndrome
3) Gamilial juvenile Parkinsonism
GDH-deficient recessive OPCA

TYPE IV: SYMPTOMATIC
a) Parkinsonian Multiple System Atrophies
1) Progressive Supra-Nuclear Palsy
2) Shy-Drager Syndrome
3) Parkinson-Dementia of Guam
b) Parkinsonism with known triggers
1) Manganese-induced Parkinsonism
2) Drug-induced Parkinsonism
c) Mechanically-induced Parkinsonism
1) Trauma
2) Space occupying lesions


I1th World congress of Neurology, Excerpta Medica, Amsterdam, p. 126.

Duvoisin RC, Gearing FR, Schweitzer MD, Yahr MD (1969) A family study of Parkinsonism. In: Progress in neuro-genetics (Eds. A Barbeau, J.R. Brunette) Excerpta Medica. Foundation, Amsterdam. pp 492-296.

Eeg-Olofsson O, Säfwenberg J, Wigertz A (1982) HLA and Epilepsy: an investigation of different types of epilepsy in children and their families. Epilepsia 23:27-34.

Elizan TS, Terasaki PI, Yahr MD (1980) HLA-B 14 antigen and postencephalitic Parkinson's disease - Their association in an AmericanJewish ethnic group. Arch Neurol 37:542-544.

Emile J, Truelle JL, Pouplard A, Hurez D (1977) Association maladie de Parkinson-antigènes HLA- $B_{17}$ et $B_{18}$. La Nouv Presse Méd 6:4144.

Kessler II (1978) "Parkinson's disease in epidemiologic perspective". Advances in Neurology 19:355-384.

Kondo K, Kurland LT, Schull WJ (1973) Parkinson's disease. Genetic analysis and evidence of a multifactorial etiology. Mayo Clinic Proc. 48:465-475.

Konigsmark B, Weiner L (1970) The olivo-ponto-cerebellar atrophies: a review. Medicine 49:227-241

Kurland LT (1958) Epidemiology: incidence, geographic distribution and genetic considerations. In: "Pathogenesis and Treatment of Parkinsonism" (Ed WS Fields) Charles C Thomas, Springfield pp 5-49.

Laberge C(1966) Prospectus for genetic studies in the French Canadians, with preliminary data on blood groups and consanguinity. Bull Johns Hopkins Hosp 118:52-68.

Lees AJ, Stern GM, Compston DAS (1982) Histocompatibility antigens and post-encephalitic Parkinsonism. J Neurol Neurosurg Psychiatr 45:1060-1061.

Leheny WA, Davidson DLW, De Vane P, House AO, Lenman JAR (1983) HLA antigens in Parkinson's disease. Tissue Antigens $21: 260-261$.

Madigand M, Oger JJF, Fauchet R, Sabouraud O, Genetet B (1982) HLA profiles in multiple sclerosis suggest two forms of disease and the existence of protective haplotypes. J. Neurol Sci 53:519-529.

Martilla RJ, Rinne UK, Thlikainen A (1981) Histocompatibility types in Parkinson's disease. J Neurol Sci 51:217-221.

Martin WE, Young WI, Anderson VE (1973) Parkinson's disease - a genetic study. Brain 96:495-506.

Mjönes H (1949) Paralysis agitans: a clinical and genetic study. Acta Psychiat. Scand., Suppl. 54, p. 1. Munksgaard, Copenhagen.

Perry TL, Bratty PJA, Hansen S, Kennedy J, Urquhart N, Dolman EL (1975) Hereditary mental depression and Parkinsonism with taurine deficiency. Arch Neurol 32:108-113.

Plaitakis A, Berl S, Yahr MD (1983) Evidence of mutation of a glutamate dehydrogenase 'Isoenzyme' in recessive olivoponto cerebellar atrophy. Ann Neurol 14:108-109.

Purdy A, Hahn A, Barnett HJM, Bratty P, Ahmad D, Lloyd KG, McGeer EG, Perry TL (1979) Familial fatal Parkinson with alveolar hypoventilation and mental depression. Ann Neurol 6:523-531.

Reed E, Lewison A, Mayeaux R, Suciu-Foca N (1983) HLA antigens in Parkinson's disease. Tissue Antigens 21:161-163.

Roy M, Boyer L, Barbeau A (1983) A Prospective study of 50 cases of familial Parkinson's disease. Can J Neurol Sci 10:37-42.

Svejgaard A, Staub-Nielsen I, Bodmer WF (1974) HLA antigens and disease. Statistical and genetical considerations. Tissue Antigens 4:95-105.

Takagi S, Shinohara Y, Tsuji K (1982) Histocompatibility antigens in Parkinson's disease. Acta Neurol Scandinav 66:590-593.

Ward CD, Duvoisin RC, Ince SE, Nutt JD, Eldridge R, Calne DB (1983) Parkinson's disease in 65 pairs of twins and in a set of quadruplets. Neurology (Cleveland) 33:815-824.

Wastiaux JP, Lamoureux G, Bouchard JP, Durivage A, Barbeau C, Barbeau A (1978) HLA and complement typing in olivo-pontocerebellar atrophy. Can J Neurol Sci 5:75-81.

Yokochi M, Narabayashi H (1981) Clinical characteristics in Juvenile Parkinsonism. In: Research Progress in Parkinson's disease (F Clifford Rose, R Capildeo, Eds) Pitman Medical, Turnbridge Wells, pp 35-39. 